\title{
THE FOREST AND CLIMATE CHANGE: EXAMPLE OF APPLICATION IN OPEN SCIENCE SCHOOLING
}

\author{
L. Mulero, M.D. Grau, I. Torra \\ Exploratori-Universitat Politècnica Catalunya (SPAIN) \\ lorena.mulero@upc.edu,dolors.grau@upc.edu, imma.torra@upc.edu
}

\begin{abstract}
This work is an application of Open Science Schooling (OSS) where schools, in cooperation with other stakeholders, become an agent of community well-being; families are encouraged to become real partners in school life and activities; professionals from enterprise, civil and wider society are actively involved in bringing real-life projects into the classroom. Specifically, it has been working with a European project: Project Erasmus+ Open Science Schooling: Fostering re-engagement in science learning through open science schooling. Developed at the secondary school Pere Fontdevila in Gironella, a direct application of OSS has been carried out around the forest. Secondary school youth work forest as a key element in the fight against the climate change and study its role in energy saving.

In a first phase of awareness of the magnitude of their role in energy saving, the students have been taking part of an action named SAVEnergy. The project SAVEnergy is promoted by Universitat Politècnica de Catalunya through the research group EXPLORATORI: natural resources. It has been installed a device that measures the electric consumption at the electric board at home of every student participating in the project. The goal is become aware of energy consumption at their own homes. From this point, and to be able to extrapolate individual energy saving and pass globally, students have worked on $\mathrm{CO} 2$ emissions into the atmosphere. For this reason, a study of the emissions from Spanish State since 2007 to 2017 has been carried out, applying statistical techniques. In addition, to saving energy and get to know how to study the effect of this savings on a global level, students have closed the cycle studying a source of renewable energy from the forest: biomass. To put their knowledge into practice and learn through the experience they have built a biomass boiler in the form of a prototype.
\end{abstract}

Studying how to fight the climate change through the forest it is essential talk about Agenda 2030. The framework of this project is the Sustainable Development Goal (SDG) number 4: Quality Education and the SDG number 13: The climate action. The activities mentioned are also in relation with the SDG 7: Affordable and clean energy and the SDG 12: Responsible consumption and production.

Taking into account the fact that the forest might seem like a distant space in the day to day of the students, it has been desired to work on the vegetation that really surrounds them: the urban woodland. This issue has been related to the SDG 3: Good health and well-being. Nowadays it is fashionable to say that the trees in the cities improve the health of the population. The trees, besides beautifying a city, provide fresh and clean air that help in the physical and mental health of its inhabitants. For these reasons, they must be thought as a public health infrastructure. In order to work about this topic, the students are now doing a study about the wooded areas in 2 cities with different size: Berga and Manresa. This work is related with the SDG 11: Sustainable cities and communities.

Keywords: Open Science Schooling, SDG, forest, climatic change

\section{INTRODUCTION}

\subsection{Forestry services}

Today, $55 \%$ of the world's population lives in urban areas, a proportion that is expected to increase to $68 \%$ by 2050 [1]. Identifying sustainable urbanization strategies is widely acknowledged as key to global sustainable development [2]. The dynamic capacity of an urban area for adequately meeting the needs of its present and future populations through ecologically, economically, and socially sound planning, design, and management activities [3] is an increasingly urgent topic in academic, planning, and policy 
circles [4]. Urban green areas generate many ecosystem services that contribute to human well-being [5] and potentially help mitigate the growing disconnection of urban residents from nature [6]. An ecosystem can be defined as "a set of interacting species and their local, non-biological environment functioning together to sustain life" [7]. Ecosystem services are defined as "the benefits human populations derive, directly or indirectly, from ecosystem functions"[8]. Social and ecological systems are interlinked and their separation is arbitrary when analyzing sustainable use of natural resources [9]. In the case of the urban environment, it is both possible to define the city as one single ecosystem or to see the city as composed of several individual ecosystems, e.g. parks and lakes [10].The borders between different ecosystems are often diffuse [11].

The 17 groups of services listed by Costanza et al. [8] are: 1.Gas regulation: Regulation of atmospheric chemical composition. 2.Climate regulation: Regulation of global temperature, precipitation, and other biologically mediated climatic processes at global or local levels. 3.Disturbance regulation: Capacitance, damping, and integrity of ecosystem response to environmental fluctuations. 4.Water regulation: Regulation of hydrological flows. 5.Water supply: Storage and retention of water. 6 .Erosion control and sediment retention: Retention of soil within an ecosystem. 7.Soil formation: Soil formation processes. 8.Nutrient cycling: Storage, internal cycling, processing, and acquisition of nutrients. 9. Waste treatment: Recovery of mobile nutrients and removal or breakdown of excess or xenic nutrients and compounds. 10.Pollination: Movement of floral gametes. 11.Biological control: Trophic-dynamic regulations of populations. 12. Refugia: Habitat for resident and transient populations. 13.Food production: That portion of gross primary production extractable as food. 14. Raw materials: That portion of gross primary production extractable as raw materials. 15.Genetic resources: Sources of unique biological materials and products. 16.Recreation: Providing opportunities for recreational activities. 17.Cultural: Providing opportunities for non-commercial uses.

\subsection{The application of Open Science Schooling}

Humans need to be in contact with nature in order to develop our comprehension above environment. In the mid-nineties the Psychologist Howard Gardner realized that the theory of multiple intelligences developed in the late 1970's and early 1980's lacked the environmental one. The eight identified intelligences include linguistic intelligence, logical-mathematical intelligence, spatial intelligence, musical intelligence, bodily-kinesthetic intelligence, naturalistic intelligence, interpersonal intelligence, and intrapersonal intelligence [12]. He defines the intelligence related to nature as "an ability to identify and distinguish among different types of plants, animals, and weather formations that are found in the natural world". Individuals draw on these intelligences, individually and corporately, to create products and solve problems that are relevant to the societies in which they live [12]. According to Gardner's analysis, only two intelligences -linguistic and logical mathematical- have been valued and tested for in modern secular schools. After his theory many hundreds of schools across the globe have incorporated MI principles into their mission, curriculum, and pedagogy [13].

This work is an application of Open Science Schooling (OSS) where schools, in cooperation with other stakeholders, become an agent of community well-being; families are encouraged to become real partners in school life and activities; professionals from enterprise, civil and wider society are actively involved in bringing real-life projects into the classroom. Specifically, it has been working with a European project: Project Erasmus+ Open Science Schooling: Fostering re-engagement in science learning through open science schooling. A direct application of OSS has been carried out around the forest developed at the secondary school Pere Fontdevila in Gironella. Secondary school youth work forest as a key element in the fight against the climate change and study its role in energy saving.

\subsection{THE SUSTAINABLE DEVELOPING GOALS}

The 2030 Agenda for Sustainable Development is a plan of action for people, planet and prosperity. All countries and all stakeholders, acting in collaborative partnership, will implement this plan. The 17 Sustainable Development Goals (SDG) (Fig. 1) and 169 targets seek to realize the human rights of all and to achieve gender equality and the empowerment of all woman and girls. The 2030 Agenda is accepted by all countries and is applicable to all, taking into account different national realities, capacities and levels of development and respecting national policies and priorities. These are universal goals and targets which involve the entire world. They are integrated and indivisible and balance the three dimensions of sustainable development: the economic, social and environmental [14]. 


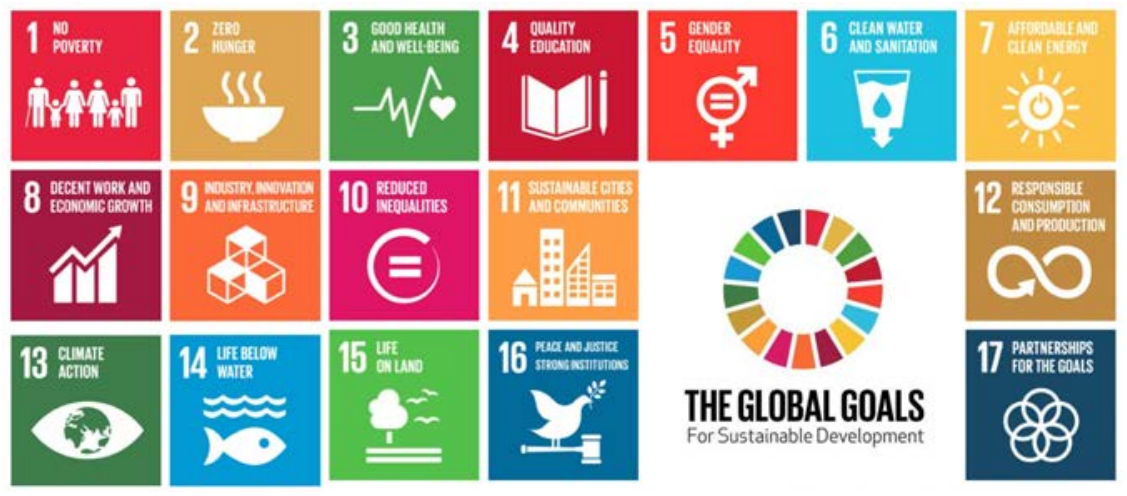

Figure 1. Sustainable Development Goals (SDG).

The new 2030 Agenda for Sustainable Development clearly reflects the importance of an appropriate educational response. Education is explicitly formulated as a stand-alone goal, Sustainable Development Goal 4. Education is both a goal in itself and a means for attaining all the other SDGs. It is not only an integral part of sustainable development, but also a key enabler for it. That is why education represents an essential strategy in the pursuit of the SDGs [15]. In Catalonia has been published the English to Catalan translation of "Education for Sustainable Development Goals: learning objectives" by UNESCOCAT in its role of disseminating and promoting the programs and projects of UNESCO in Catalonia.

\section{METHODOLOGY}

It has been working with one Secondary School to carry out a pilot test of the project. The phases carried out were: 1. Preliminary measurement of $\mathrm{CO}_{2}$ emissions linked to electrical consumption of students in their homes; 2. Implementation of the SAVEnergy project; 3. Measure of the $\mathrm{CO}_{2}$ emissions linked to the electrical consumption of the students after the implementation of the SAVEnergy project and 4. Calculation of the tree surface in the areas where the students that develop the project live.

Following the action structure, an amount of interactive activities has been designed to work some of the forests' services of Costanza listed above. Manuals (Fig. 2) for the correct development of the activities have been developed: Manual for calculation of $\mathrm{CO}_{2}$ emissions linked to daily energy consumption of students and Manual for the study of tree surface.
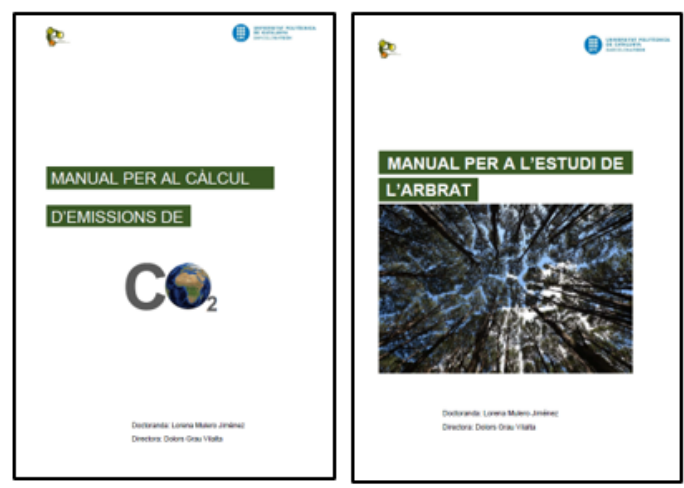

Figure 2. Manuals for calculation of $\mathrm{CO}_{2}$ emissions and for the study of tree surface.

\subsection{Calculation of $\mathrm{CO}_{2}$ emissions}

The Manual for the calculation of $\mathrm{CO}_{2}$ emissions is intended to facilitate the activities to be carried out in the study of air pollution and the calculation of $\mathrm{CO}_{2}$ emissions by the student from any secondary school. The proposed activities are structured in the following blocks: Block I Study of the quality of the air in the area where the students live; Block II Calculation of the reduction of $\mathrm{CO}_{2}$ emissions associated with the energy saving controlled by the Mirubee device; BLOCK III Calculation of the reduction of $\mathrm{CO}_{2}$ emissions associated with the energy savings that would be used by public transport instead of private 
vehicles and BLOCK IV Calculation of the reduction of $\mathrm{CO}_{2}$ emissions associated with the consumption savings water.

To calculate $\mathrm{CO}_{2}$ emissions related to the daily activities of the student, the greenhouse gases Emission Calculator [16] (Fig. 3) was used. Published by the Catalan Office for Climate Change [17], this calculator includes the latest emission factors available, and estimates the emissions associated with different activities. Specifically, it is used to estimate the emissions derived from energy consumption and transport, the fugitive emissions of fluorinated gases, the emissions derived from municipal waste management and the emissions generated by water consumption in urban networks. In order to facilitate its use, the Calculator gives the option to enter the activity variables with different units, and includes a Summary tab where emissions are collected by categories. The classification of emissions by range is made in accordance with internationally recognized methodologies (ISO 14064, part 1 and ISO / TR 14069).

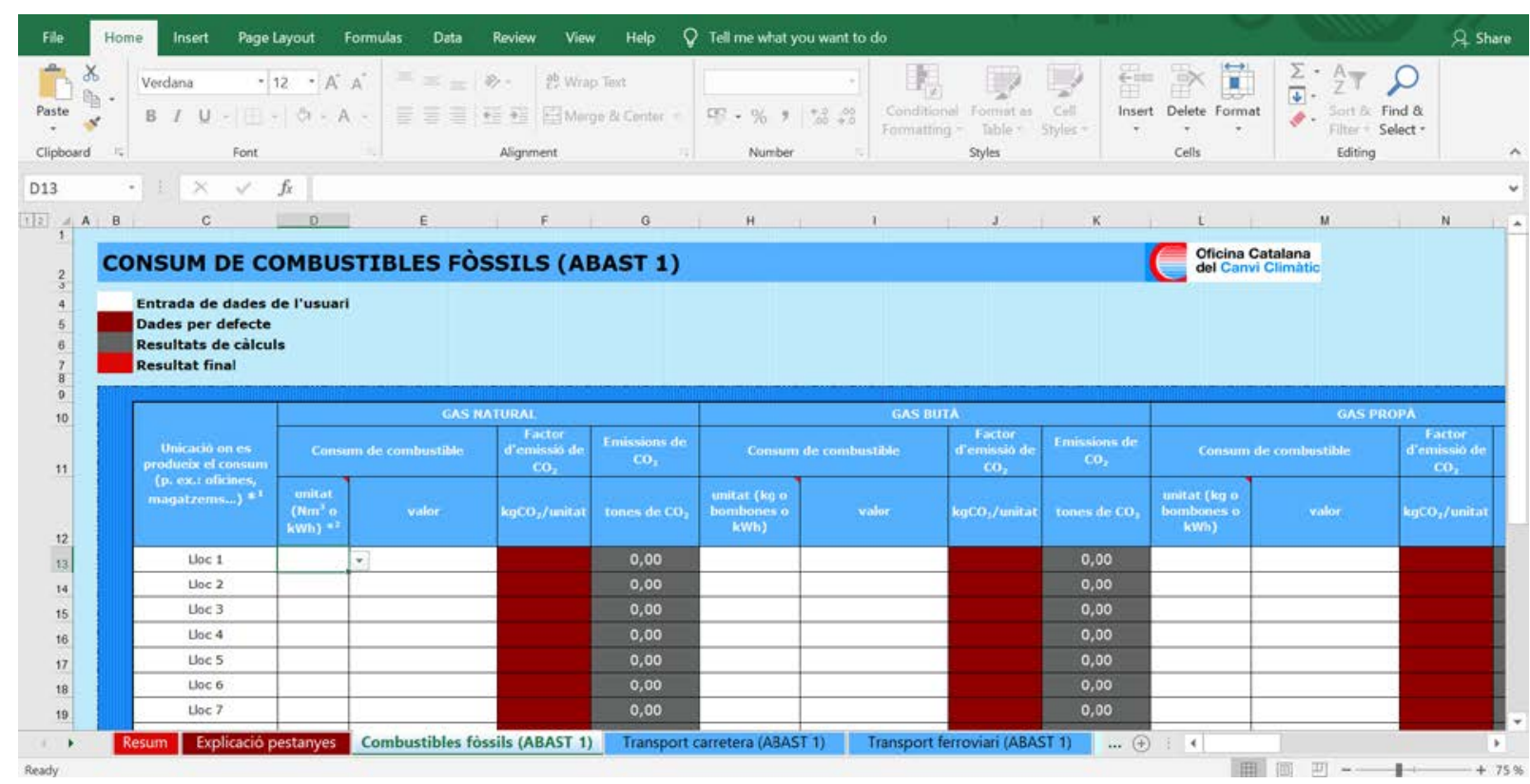

Figure 3. $\mathrm{CO}_{2}$ Calculator.

\subsection{SAVEnergy}

The main objective of this initiative is to carry out actions aimed at young people from the Secondary School in order to stimulate energy savings, in their secondary schools and especially in their own homes. Likewise, it is about causing the teaching staff of the secondary schools themselves to be the co-directors and take part as co-creators of the project, in order to involve the whole environment of young people: teachers and their families. The involvement of various sectors of society is encouraged: Educational Centers, University, Administration, Local Companies, Families ... [18] so that the project has an echo that allows to give more visibility to the energy savings achieved, and end up having an important local impact. In order to further promote the interest of young people, several e-learning systems have been used: firstly, the data capture system through a mobile application (Fig. 4) and secondly, it has developed a virtual platform that allows them to track their evolution, compare results among the different participants, and propose ideas. These data and ideas can be used to compare the results between: (i) students in the same classroom; (ii) Classrooms of the same School, and (iii) Secondary Schools of the same Region. The platform allows to resort to gamification techniques. The competition and reaching certain goals (points, rankings, ...) gives an added value to the action. 


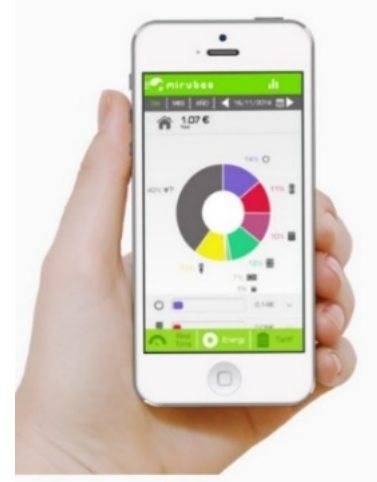

Figure 4. Mirubee mobile app.

In order to be as close as possible to situations of real life, the participation of different sectors of society, which contribute to the non-formal development of education, is fundamental. These sectors are grouped into three environments: 1. Knowledge (Centres, other teachers, families and university institutions). 2. Political Agents (Local- Regional - National). 3. (Industry/Company/Research). The management of the Institute, in close collaboration with Universitat Politècnica de Catalunya (UPC), is the engine of the entire project. Its implication has as a function the leadership and involvement of the rest of the groups, in such a way that it carries out the following tasks: Presentation of the work plan to the faculty of the Centre; Information to families; Extraction of conclusions and writing of the final report with the students. That's a clear example of application of OSS. The project has been implemented as pilot test in three Secondary Schools.

Materials and media required are: the equipment for the registration and monitoring of the energy consumption (electricity) of the buildings of the School and the equipment for the registration and monitoring of the energy consumption (electricity) at the home of the students. Once the equipment is installed in the homes of the students (the installation is carried out by the City Hall), teachers inform them of their operation and they are provided with a manual in order to be able to connect the computer to the home wifi. After 15 days of testing, another manual is given to the students in order to let them know how to participate actively in the Forum on the SAVEnergy page. Each student enrols in the page with an "Alias" that the teacher knows. From that point on, the real measurements of energy consumption in the homes of young people are already beginning to take into account. The responsible professor is doing the vacuum periodically every 15 days. With the data of the daily consumption of this period (collected in an Excel file), the evolution of the energy consumption for each participant can be observed. In this way, every time the emptiness is made, students can adjudge the medals and points that are visible on the SAVEnergy website. The Table 1 shows how the medals are awarded based on different criteria, which young people can know beforehand by consulting the Manual "How do I get points and medals": Most sparing users; Most active users; Most winnings.

Table 1. SAVEnergy medals.

\begin{tabular}{c|c|c|c}
\hline \hline Medal & \multicolumn{2}{c}{ Characteristics } & \multicolumn{2}{c}{ Characteristics } \\
\hline 14 & $\begin{array}{c}\text { Gold Medal on Savings: } 100 \text { Points } \\
\text { Savings. For having saved more than } \\
5 \% \text { on the reference measurement. }\end{array}$ & $\begin{array}{c}\text { We open the medal - get it on entering } \\
\text { the website for the first time. }\end{array}$ & $\begin{array}{c}\text { Prize to the irreducible saviour: } \\
\text { awarded to obtain two consecutive } \\
\text { gold medals for savings. }\end{array}$ \\
\hline & $\begin{array}{c}\text { Silver Medal for Savings: } 50 \text { Points } \\
\text { Savings. For saving between } 2 \% \text { and } \\
5 \% \text { on the reference measurement. }\end{array}$ & $\begin{array}{c}\text { Medal to the early saviour: awarded to } \\
\text { get a gold medal at the first } \\
\text { measurement. }\end{array}$ \\
\hline
\end{tabular}




\subsection{Urban forest}

The Manual for the study of tree surface is intended to facilitate the activities to be carried out in the study of the cover of the soil and the trees of any area of the territory of Catalonia. In order to develop the activities and study the trees surfaces, work is done using the Mapa de Cobertes del Sol de Catalunya (MCSC), a thematic mapping of high resolution of the main types of roofs of the country's land (forests, crops, urban areas, etc.). The MCSC is carried out at the Centre de Recerca Ecològica i Aplicacions Forestals (CREAF), with funding from the Generalitat de Catalonia. MCSC is part of Cartography of Generalitat de Catalunya available on the Internet and is, therefore, free of use. The MCSC is presented in digital format. The different surfaces are delimited by photointerpretation and digitization on a computer screen, through the SIG MiraMon. Through this Reader MiraMon students can study the surface area with several levels of precision [19].

\section{RESULTS}

\subsection{Calculation of $\mathrm{CO}_{2}$ emissions}

Students have their first contact with the air quality measures. Below are some students' reflexions: "Looking at the map (Fig. 5), a month and a half later from the Manual measurement, I have seen that in the same town the quality of the air has changed. In the middle of March there were composed of those that did not have data and others that did not measure. At the beginning of May, however, I could see that four compounds could be measured and that the quality of all of these was good. In addition, I have been able to compare the amount of each compound in the air and how it has changed in more and more". "'I have seen that there are many areas of special protection in Barcelona, however in other areas of Catalonia, such as mountain areas, where the air is not so polluted, there aren't (Fig. 6)"

\section{Qualitat de l'aire actual Qualitat de l'aire actual}

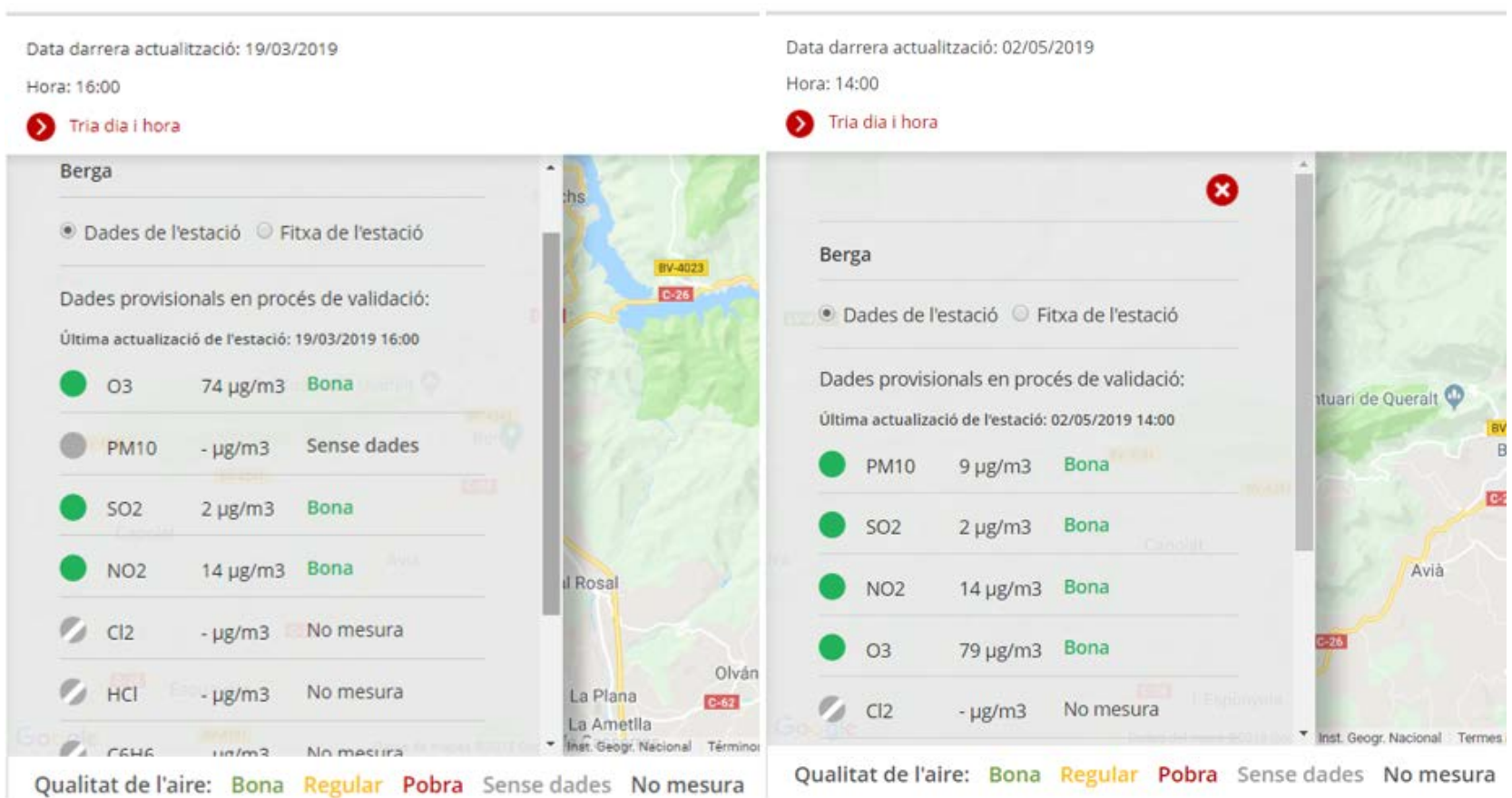

Figure 5. Example of air quality. 


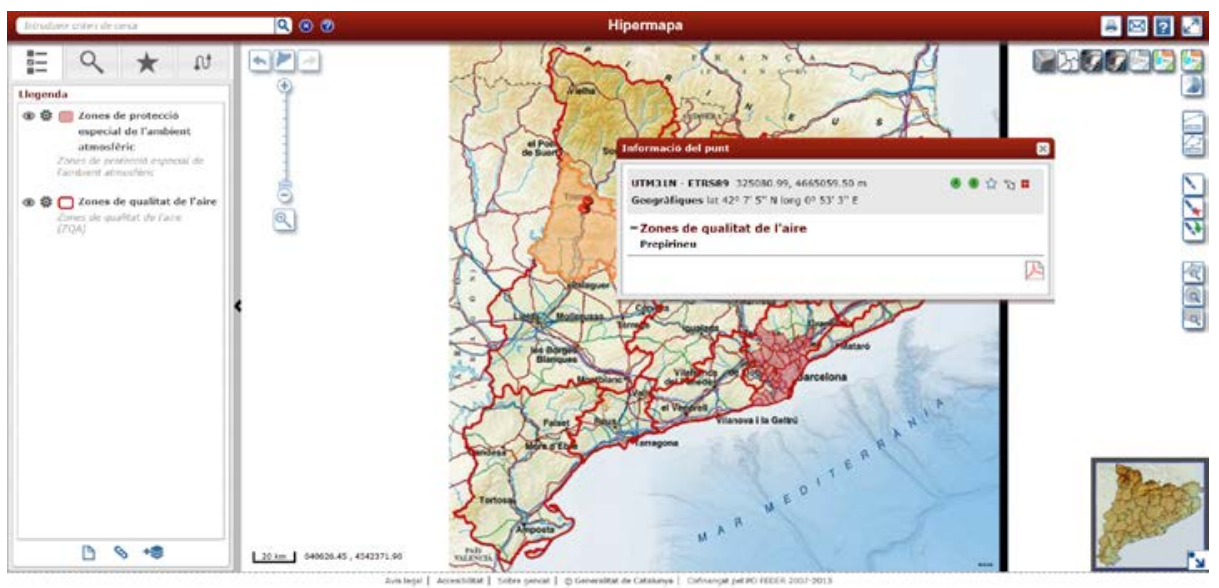

Figure 6. Example of air quality map.

Students, in addition to the activities proposed in the Manual for the calculation of $\mathrm{CO}_{2}$ emissions, have developed other studies whose results have been uploaded to the website of the Secondary School. In the first place, they have done a study of the broadcasts of the Spanish State from 2007 to 2017, applying the statistical techniques worked in the classroom. Secondly, they have studied emissions by geographical blocks. Finally, the spreadsheet of the emissions of all countries has been prepared by ordering them based on different criteria: countries with more emissions in absolute terms; countries with more emissions in relative terms depending on the inhabitants; countries with more emissions in relative terms depending on the surface; countries with less emissions in absolute terms; countries with less emissions in relative terms depending on the inhabitants; countries with less emissions in relatives terms depending on the surface, countries with less decrease of emissions in absolute terms, countries with less decrease of emissions in relation with the emitted before, countries with the most decrease of emissions in absolute terms.

\subsection{SAVEnergy}

Throughout a period of one month, equivalent to two data sets, you can see the evolution of the project (Fig. 7). Students seeing the ranking are more motivating and participating more actively and manage to maximize energy savings. This fact is also reflected in some of the comments that hang in the Forum, where they indicate what savings measures are being implemented in order to reduce consumption. The winning student of the most awarded users is given a recognition diploma and can stay with the Mirubee device in their home, in order to continue controlling the energy consumption. The awards ceremony is held at an event in which families are invited, and the City Hall that has contributed to the project.

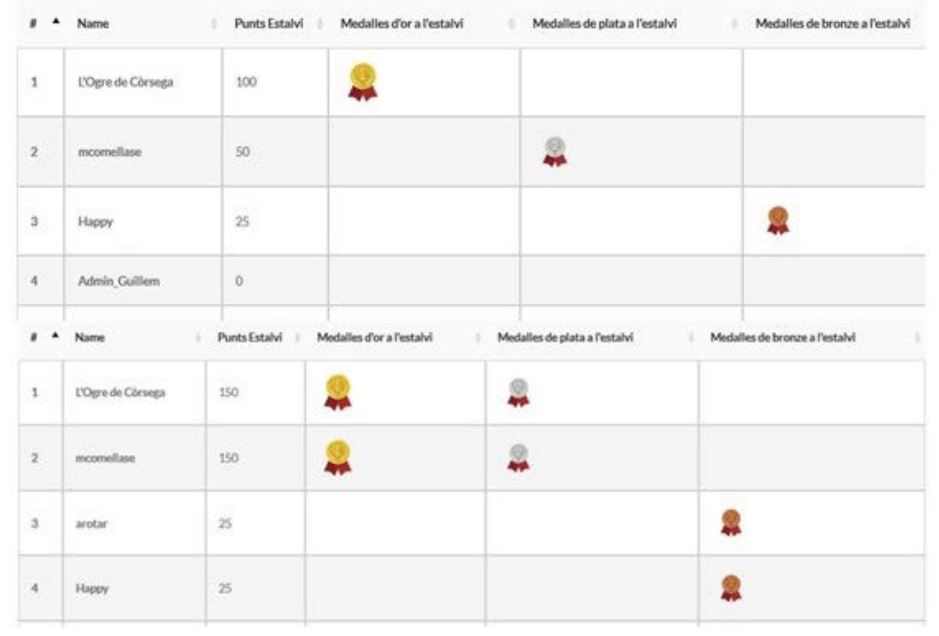

Figure 7. Comparison between most sparing users. 


\subsection{Tree surface}

Students know their forest environment thanks to the activities developed in the study of the trees that surround the areas where they live. Below is the reflection of a student: "doing this activity I have been able to see the different areas that are near my city, and what surprised me most has been to find that there is a small area burned next to the urban centre (Fig. 8). With Miramón I could see the burned surface of this particular area. Besides, I have also seen the forest areas near my town, which I did not know".

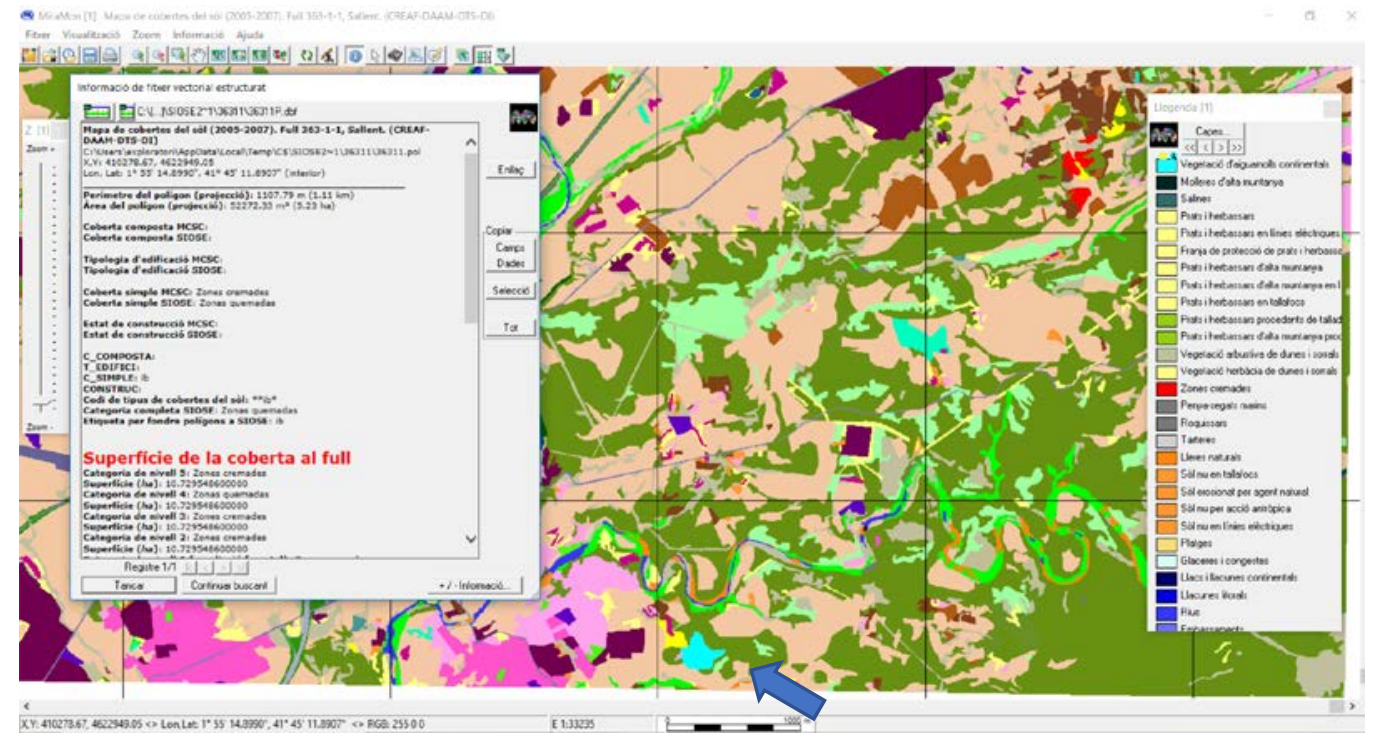

Figure 8. Small burned area in a tree surface map.

\subsection{SDG}

Studying how to fight the climate change through the forest it is essential talk about Agenda 2030. The framework of this project is the Sustainable Development Goal (SDG) number 4: Quality Education and the SDG number 13: The climate action. As it had been forecast previously for the realization of the project, activities mentioned are also in relation with the SDG 7: Affordable and clean energy and the SDG 12: Responsible consumption and production. Working on the vegetation that surrounds the students, the urban woodland, it is clear that this issue is related to the SDG 3: Good health and wellbeing. Nowadays it is fashionable to say that the trees in the cities improve the health of the population. The trees, besides beautifying a city, provide fresh and clean air that help in the physical and mental health of its inhabitants. For these reasons, they must be thought as a public health infrastructure. Studying about the wooded areas in 2 cities with different size: Berga and Manresa, this work is related with the SDG 11: Sustainable cities and communities. Fig. 9 shows the relationship between the forest issues, the contents explained in [20] and their relation with the SDG corresponding to each one.

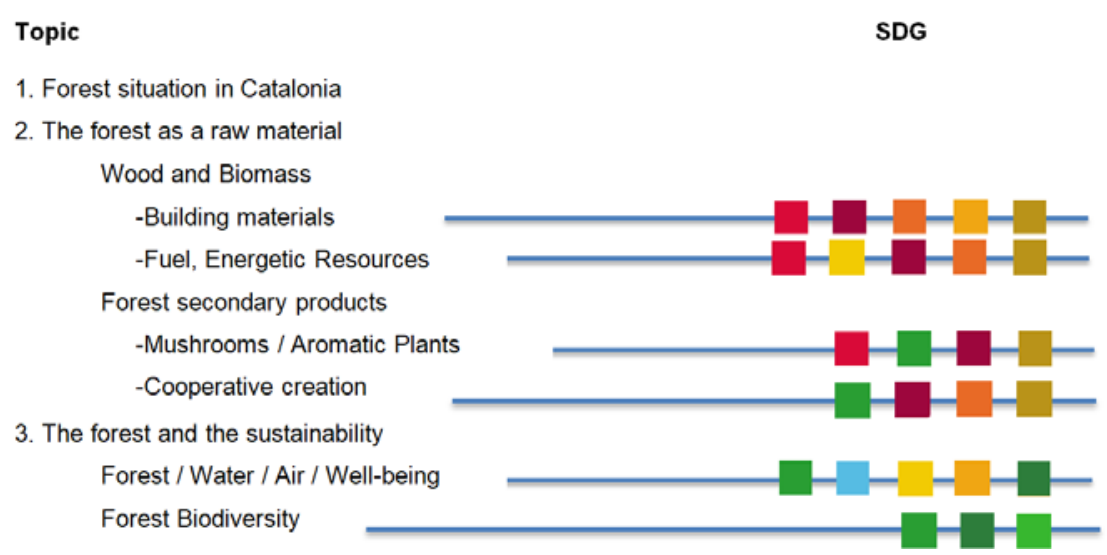

Figure 9. Relationship between forest issues and SDG. 


\subsection{Knowledge Fair}

The Knowledge Fair (Fig. 10) aims to divulge and share research projects related to the science and technology of the Universitat Politècnica de Catalunya and of different research centres. The aim is to increase young people's interest in research in order to awaken scientific vocations and to demonstrate that science is within everyone's reach. Students of the project shown the results of their own work to other students who were visiting the Fair.
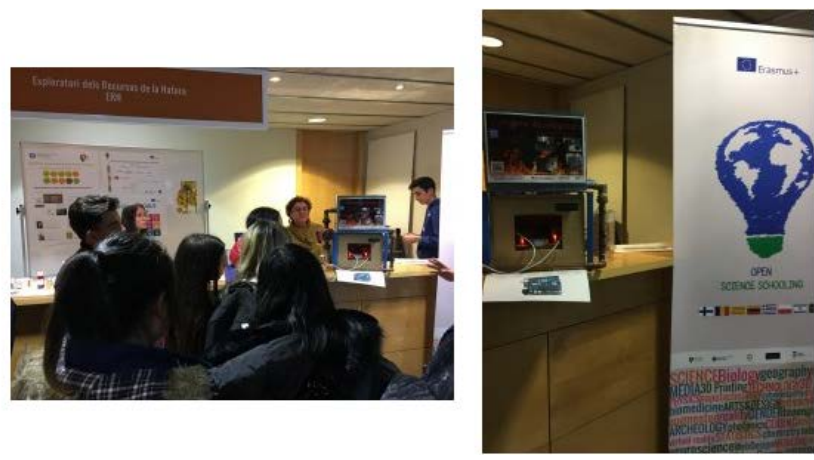

Figure 10. Project exhibition at the Knowledge Fair

\section{CONCLUSIONS}

The Open Schooling methodology can give a much wider perspective to young people, as it allows to solve real life problems, and improve the involvement of different sectors of society in the teaching / learning of youth.

In the 21st century, energy savings is a priority. The OSS and the Forest project can contribute to mentoring the society of this fact, promoting savings in youth so that they become the engine of this change. The most creative and innovative aspects of the project are the involvement of the Secondary Schools, through the empowerment of the teaching staff, and of the families together in the project and the development and use of the virtual platform. That makes the students the centre of the project (main actors). Provide facilities for measuring and controlling energy consumption in the Secondary School where they learn how to operate, and have at home an added value for their responsibility and a very important multiplier effect on the initiative. In the classroom, the students themselves can see how the reduction of energy consumption in the School and at home is evolving, as well as their contribution to the reduction of $\mathrm{CO}_{2}$ emissions. In addition, the use of techniques of "social Gamification" and e-learning as a tool encourage participation in the project. Finally, the families of the students are the components of the project that close the circle, in such a way that their involvement is fundamental so that the project is successful.

The design of activities around the Forest and based on the fulfilment of SDG is linked to the Education for Sustainable Development (EDS). This can contribute to achieving the SDGs by, first, developing cross-cutting sustainability competencies that are needed to deal with many different sustainability challenges and to relate the different SDGs to each other. Second, ESD can equip learners with the specific cognitive, socio-emotional and behavioural learning outcomes that enable them to deal with the particular challenges of each SDG [15]. It should be noted that the activities plan is in development nowadays so there are some exercises done and other in process or programmed for the following months.

\section{REFERENCES}

[1] United Nations, "World Urbanization Prospects : The 2018 Revision," United Nations Econ. Soc. Aff., pp. 1-2, 2018.

[2] FAO, "Climate change and food security: a framework document". Food and Agriculture Organization of the United Nations: Rome, 2008. Retrieved from: http://www.fao.org/forestry/ 15538-079b31d45081fe9c3dbc6ff34de4807e4.pdf. Accessed Feb 2019 
[3] Wu J, "Making the case for landscape ecology: an effective approach for urban sustainability". Landscape Ecol, vol. 27 no. 1, pp. 41-50, 2008.

[4] K. H. Clark and K. A. Nicholas, "Introducing urban food forestry: A multifunctional approach to increase food security and provide ecosystem services," Landsc. Ecol., vol. 28, no. 9, pp. 1649-1669, 2013.

[5] Chiesura, A. "The role of urban parks for the sustainable city". Landscape and Urban Planning, vol. 68, no. 1, pp. 129-138, 2004.

[6] Pyle, R. M. The thunder tree: lessons from an urban wildland., Boston, Massachusetts, USA: Beacon Press, 1993.

[7] Moll, G., Petit, J., "The urban ecosystem: putting nature back in the picture", Urban Forests vol.14, no. 5, pp. 8-15, Oct-Nov 1994.

[8] R. Constanza et al., "The Value of the World's Ecosystem Services and Natural Capital", Nature, vol. 387, no. 15, pp. 253-260, May 1987.

[9] Berkes, F., and C. Folke., Linking social and ecological systems: management practices and social mechanisms for building resilience., Cambridge, UK: Cambridge University Press, 1998.

[10] Rebele, F., "Urban ecology and special features of urban ecosystems". Global Ecol. Biogeography Lett. vol. 4, no. 6, pp. 173-187, Nov 1994.

[11] S. Bolund, Permar and Hunham, "Ecosystem services in urban areas," Ecol. Econ., vol. 29, no. 2, pp. 293-301, 1999.

[12] Gardner, Howard. The Disciplined Mind: What All Students Should Understand. New York: Simon \& Schuster, 1999.

[13] Gardner, H. Frames of mind: The theory of multiple intelligences, New York: Basic Books, 1983.

[14] UNESCO, Transforming our world: the 2030 Agenda for Sustainable Development, 21 October 2015, A/RES/70/1, Retrieved from:

https://sustainabledevelopment.un.org/post2015/transformingourworld.html

[15] UNESCO, "Education for Sustainable Development Goals: learning objectives", 2017, ED/446, available at: https://unesdoc.unesco.org/ark:/48223/pf0000247444

[16] http://canviclimatic.gencat.cat/ca/detalls/Article/Calculadora-demissions. Accessed Feb 2019

[17] http://canviclimatic.gencat.cat/ca/inici. Accessed Feb 2019

[18] E. Hazelkorn et al., "Science Education for Responsible Cityzenship", European Commission, 2015

[19] http://www.creaf.uab.cat/miramon/mmr/cat/. Accessed Feb 2019

[20] L. Mulero, I. Torra, M.D. Grau, "Open Schooling: application in the study of the forest", INTED2019 Proceedings, pp. 8487-8494, 2019. 